\title{
Attitudes Towards Psychiatry in Lebanese Medical Students: What Are the Factors that Could Lead to a More Favorable Outlook?
}

\author{
Saïd El Hage ${ }^{1} \cdot$ Léa Daou $^{1}$ (D) $\cdot$ Georgio Sayde ${ }^{1} \cdot$ Michael Daaboul $^{1} \cdot$ Souheil Hallit ${ }^{2} \cdot$ Pascale Salameh $^{1}$
}

Received: 4 November 2020 / Accepted: 20 April 2021 / Published online: 3 May 2021

(C) Academic Psychiatry 2021

\begin{abstract}
Objective The authors aimed to assess the attitudes towards psychiatry of all Lebanese medical students, as well as the factors that could have led to these attitudes, whether favorable or not.

Methods In this cross-sectional study, the authors ran a questionnaire among a sample of Lebanese medical students from all medical faculties, regions in Lebanon, and years of medical school, using the ATP-30 scale and the WHO-5 well-being index. The answers from the 607 participants were statistically analyzed on SPSS version 23.0.

Results Among participants, $95.1 \%$ had a positive attitude towards psychiatry, reflecting a favorable outlook among Lebanese medical students overall. The average ATP-30 score in our sample was 111.95 out of 150 (SD =12.55), which is in the range of countries of higher socio-economic level such as Germany and Switzerland. Also, 26.5\% of participants reported that they consider psychiatry as a potential career choice. No demographic factor had any influence on the ATP-30 score. In the multivariate analysis, only two factors resulted in favorable attitudes: exposure to a patient with a diagnosed psychiatric illness in the student's surroundings and a lower WHO-5 well-being index.

Conclusion This study's results do not fit into the traditional "developed vs. developing countries" paradigm. However, Lebanon still has a lot of challenges to face in order to provide quality mental healthcare.
\end{abstract}

Keywords Psychiatry $\cdot$ Medical students $\cdot$ Attitudes $\cdot$ Lebanon

In Lebanon, a Middle Eastern Arab country, as the Lebanese population is crawling under the burden of political instability, social unrest, and economic crisis, the need for psychiatrists might hit alarming proportions. Available data from 2006 has shown the effect of such critical situations on the Lebanese population: after experiencing armed conflicts, $29.3 \%$ of village residents within a few miles of the Israeli border were victims of PTSD [1]. At that time, these findings shed light on the importance of Lebanese governmental planning and allocation of more funds in favor of the mental health sector. Nonetheless, an assessment conducted by the WHO in Lebanon in 2010 reported that only $5 \%$ of the public health sector budget is spent on mental health [2].

When reflecting on the possible obstacles that could lead to an eventual shortage in the psychiatrist workforce in Lebanon,

Léa Daou

lea.daou1997@gmail.com

1 Lebanese University, Beirut, Lebanon

2 Holy Spirit University of Kaslik, Beirut, Lebanon one could think of a negative attitude of current medical students towards psychiatry as a medical field. Data regarding the Lebanese general population's knowledge, attitudes, and behaviors towards patients with mental disease are available, and the general figures were not very favorable [3]. Lebanon was also suggested to have the fourth highest prevalence of any mental disorder among fifteen other surveyed countries [4]. Data from 2002 to 2003 has also shown that the 12-month prevalence of mood and anxiety disorders was $6.6 \%$ and $11.2 \%$, respectively, in a Lebanese sample. Shockingly, only $3.7 \%$ of subjects and only $14.6 \%$ of those with severe mental disorders were treated. These were the lowest percentages among the 15 surveyed countries [4]. Lebanon is also part of the Arab world, where mental health is still surrounded by stigma. As a matter of fact, in a study conducted by AlKrenawi, it was found that patients in the Arab world tend to express their psychological struggles in terms of physical symptoms to bypass the stigma [5]. Another common practice in the Arab world reported by the same study is the reliance on religious figures to cure psychiatric disorders.

However, the attitude of Lebanese medical students towards psychiatry has not been assessed to date. Many studies 
conducted on students from the medical and paramedical field around the world have been using the ATP-30 (Attitude Towards Psychiatry) scale, which was established in 1982 by Burra et al. [6]. Using this scale, medical students in a neighboring country, Egypt, were found to have a generally positive attitude towards psychiatry [7].

This study aims to quantitatively assess the attitudes of medical students, in the seven medical schools of Lebanon, towards psychiatry, using the ATP-30 score. The authors will then identify factors that could influence the outlook of Lebanese medical students towards psychiatry. This data could give an insight into the future of mental health and psychiatry in Lebanon.

\section{Methods}

\section{Study Design and Participants}

This cross-sectional study was conducted in May 2020 in Lebanon. The sample consisted of Lebanese premedical and medical students from the first until the seventh year of medical education and attending any of the seven medical faculties in Lebanon: American University of Beirut (AUB), Lebanese American University (LAU), Lebanese University (LU), University of Saint Joseph (USJ), University Of Balamand (UOB), Holy Spirit University of Kaslik (USEK), Beirut Arab University (BAU). Among the pre-medical students, only those intending to pursue a medical education were asked to answer the questionnaire.

It is noteworthy that there is no homogeneity in the distribution of the years of medical education in the seven Lebanese medical schools between pre-medical and medical years. However, in all of the faculties, the MD (medical doctor) degree is acquired after 7 years and includes theoretical courses and clinical training.

Participants were from all seven provinces of Lebanon (Beirut, Mount Lebanon, North, South, Bekaa, BaalbekHermel, and Nabatieh).

Any student in the paramedical field or any graduated medical student (resident, physician) was excluded from this study.

\section{Sample Size}

Using Slovin's Formula, with a 4\% margin of error and a total estimated population of 5600 medical students, the total required sample would be 563 [8]. Data collection yielded 607 responses. Therefore, the response rate is $10.83 \%$.

\section{Tests and Procedures}

Data collection was done using a questionnaire in the English language. Researchers distributed the questionnaire via a widely used platform in Lebanon (WhatsApp). The survey was sent to comprehensive groups created by medical students themselves.

Researchers ensured that the form was sent to every university and every medical year group.

The link to the questionnaire, sent on WhatsApp groups, was inactivated once the required sample size was reached and even exceeded.

\section{Questionnaire Development}

The questionnaire included three sections: the sociodemographic section, the ATP-30 scale, and the WHO-5 scale. The socio-demographic part contained information about the biological sex, university, and academic year of each participant along with the region (province) of residence.

The ATP-30 scale (Attitude Towards Psychiatry) is a scale used for medical and paramedical students, which measures the attitudes towards psychiatry as a medical specialty. ATP-30 is a 5-point Likert scale (1: strongly agree-5: strongly disagree or vice versa according to the statement), composed of 30 questions with a total score varying from 30 to 150 . It contains 15 positive phrases (questions 4, 5, 9-12, 14, 15, 18, 20, 23, 25, 27-29) and 15 negative phrases (1-3, 6-8, 13, 16, 17, 19, 21, $22,24,26,30)$. Positive phrases are reversed by subtracting each item by 6 [6]. Scores of more than 90 represent a positive attitude towards psychiatry, while scores of less than 90 represent a negative attitude. A score of 90 indicates a neutral attitude towards psychiatry. Moreover, reliability analysis of the ATP30 scale showed a Cronbach $\alpha$ of 0.872 , which indicates good internal consistency between the items of the scale.

The third part of the questionnaire consisted of the WHO-5 well-being index, a tool used to measure current mental wellbeing. The scale is composed of five questions with a score of 0 to 5 for each. The total score of these five items is subsequently multiplied by 4 , resulting in a score between 0 (reflecting the worst possible mental state) and 100 (reflecting the best possible one) [9]. This index was added to the study since data collection was conducted during the COVID-19 pandemic and economic crisis in Lebanon. Participants' opinions and attitudes could have been affected by it. The Cronbach $\alpha$ for the WHO-5 items was equal to 0.867 , which indicates good internal consistency; thus, the scale is reliable.

\section{Statistical Methods}

Data was automatically generated, using the Google form, into an Excel file; the latter was transferred into an SPSS sheet, and analysis was performed using SPSS version 23.0. 
A descriptive analysis was performed first, showing means and standard deviations for continuous variables, and frequencies and percentages for multinomial variables. Student's $t$ test was used to compare continuous variables (including the scales), while the chi-square test was used to compare multinomial variables. One-way ANOVA test compared means of ATP-30 scores between years of medical education.

Finally, a multivariate logistic regression analysis was conducted in order to reveal significant factors affecting the ATP30 score in medical students, taking into consideration all factors (gender, university, year of medical education, location, WHO-5 well-being scale, religiosity, and known psychiatric illness in surroundings). The multivariate analysis intends to reveal any significant association from the factors mentioned above with the ATP-30 score. The latter was divided into two categories, the first category being an ATP-30 score of less or equal to 90 and the second one being a score of more than 90 . The use of logistic regression in this analysis is supported by similar studies, including Shalaby, 2015 [7]. A $p$ value of less than 0.05 was considered significant in this study.

\section{Ethical Approval}

The Psychiatric Hospital of the Cross Ethics and Research Committee approved this study protocol (IRB approval number: HPC-015-2020). Participants have been informed that this study is anonymous and participation is voluntary.

\section{Results}

\section{Sample Characteristics}

Among the 607 participants, females accounted for 351 responses (57.7\%), while males accounted for 257 (42.7\%). In Lebanon, seven medical faculties are currently teaching medicine and are distributed into one public university, the Lebanese University, and six private faculties (AUB, BAU, LAU, UOB, USJ, and USEK). The public sector accounted for 312 total responses $(51.4 \%)$, while the private sector accounted for 294 (48.6\%). Furthermore, responses from private university students were divided as follows: USJ presented 62 responses $(10.2 \%)$, UOB 100 responses (16.4\%), USEK 37 responses $(6.1 \%)$, AUB 38 responses (6.3\%), LAU 25 responses $(4.1 \%)$, and BAU 33 responses $(5.4 \%)$.

As for the years of medical education, 124 students $(20.4 \%)$ were in their first year of medical education, 56 $(9.2 \%)$ were in the second year, $75(12.3 \%)$ were third-year students, $123(20.2 \%)$ were fourth-year students, $123(20.2 \%)$ were fifth-year students, and $67(11 \%)$ and 40 (6.6\%) were in the sixth and seventh-year respectively.

Average ATP-30 scores of medical students in private universities are higher than the scores of the Lebanese University students (public sector) throughout all medical years, despite both being high (scores > 108) (Fig. 1). However, an independent $t$ test revealed that only fifth-year students had significantly higher ATP-30 scores in private universities than in the public university (mean difference $=5.63, p$ value $=0.013$ ).

\section{ATP-30 Score}

The average ATP-30 score in our sample was 111.95 out of 150 ( $\mathrm{SD}=12.55)$. The lowest ATP-30 score was 73, and the highest was 148 . Moreover, $95.1 \%$ of participants had a positive attitude towards psychiatry, while only $4.8 \%$ had a negative attitude towards psychiatry. Since only one participant reported a neutral attitude towards psychiatry, negative and neutral attitudes were grouped into a single category to simplify subsequent statistical analysis.

\section{Factors Affecting ATP-30 Scores}

Chi-square test revealed that the year of medical school did not have a significant impact on ATP-30 scores $\left(\chi^{2}=6.61, p\right.$ value $=0.359)$. There was also no significant difference in ATP-30 scores between provinces in Lebanon $\left(\chi^{2}=2.93, p\right.$ value $=0.818$ )

Concerning gender, ATP-30 scores did not show a significant difference between males and females $(p$ value $=0.21)$ (Table 1). Overall, both genders had a very high proportion of favorable attitudes towards psychiatry. Likewise, the chisquare test revealed that religiosity did not influence ATP-30 scores $(p$ value $=0.51)($ Table 1$)$.

Interestingly, participants who were in contact with someone in their surroundings with a psychiatric condition such as depression, schizophrenia, bipolar disorder, and other disorders scored significantly higher on the ATP-30 scale than participants who do not recall knowing any psychiatric patient (97.2\% vs. 93.2\%, respectively, and $p$ value $=0.013)$.

An independent sample $t$ test was used to compare means of WHO-5 well-being index scores among favorable and nonfavorable ATP-30 score groups. Results showed a negative correlation between WHO-5 and ATP-30 score. Participants with an ATP-30 score $\leq 90$ had an average WHO-5 of 60.67 (S.D. = 21.09), while participants with ATP-30 scores $>90$ had an average WHO-5 of 52.19 (mean difference $=8.47, p$ value $=$ 0.024).

\section{ATP-30 Selected Answers}

Table 2 presents answers to selected questions in the ATP-30 scale. Most notably, $26.5 \%$ of students would like to be psychiatrists when combining the "Agree" and "Strongly agree" answers ( $p$ value $<0.001)$. When asked about psychiatric patients as being more interesting to work with, $32.6 \%$ had a neutral opinion, while $54.1 \%$ agreed/strongly agreed and only 
Fig. 1 Variation of average ATP30 score throughout years of medical education in public and private universities

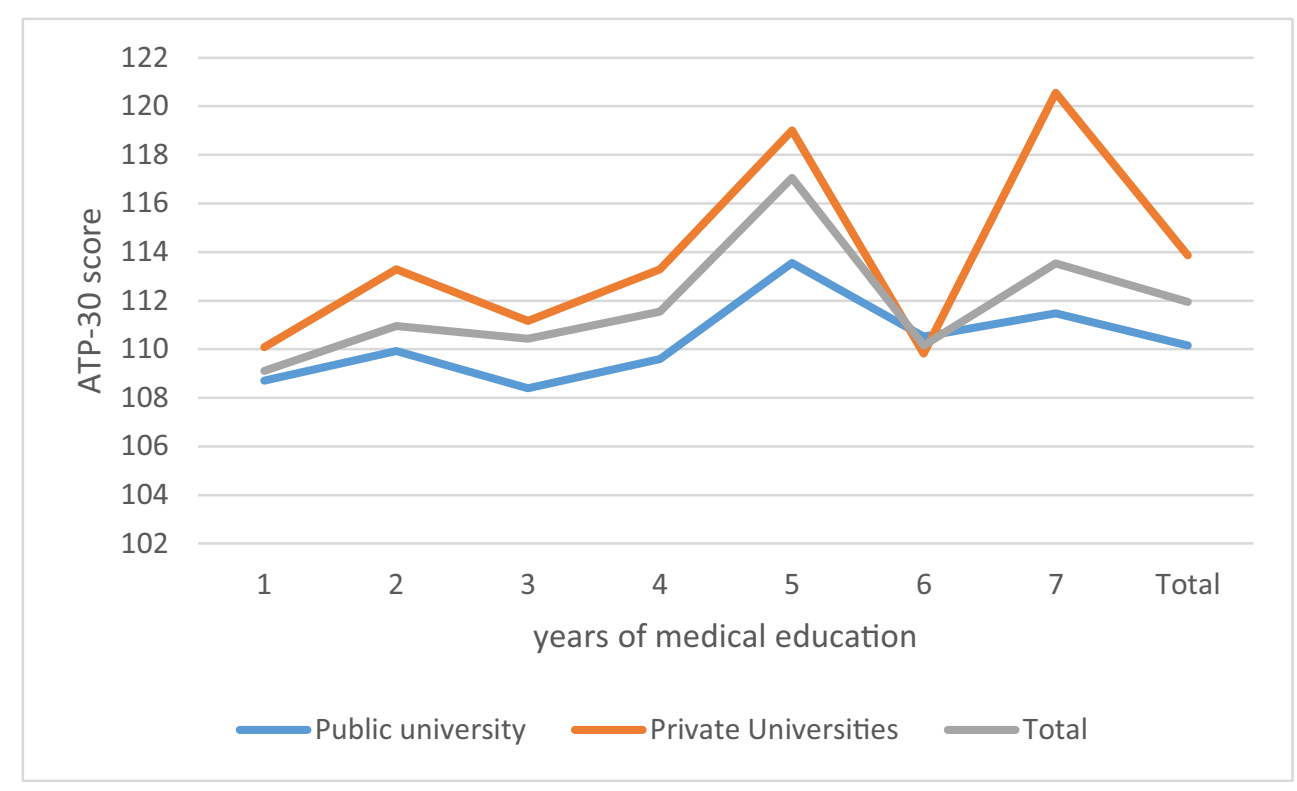

$13.3 \%$ disagreed/strongly disagreed ( $p$ value $<0.001$ ). Only $14.5 \%$ agreed/strongly agreed that "Psychiatry has very little scientific information to go on," while $48.8 \%$ disagreed and $16.5 \%$ strongly disagreed. Lebanese medical students who disagreed/strongly disagreed that psychiatry is the most essential part of the curriculum in medical schools these days make up $33.1 \%$ of the sample, whereas $32 \%$ were neutral to this statement, and $34.9 \%$ agreed/strongly agreed to it.

\section{Multivariate Analysis}

Multivariate analysis revealed that, out of all the factors studied, only the WHO-5 well-being index and known psychiatric

Table 1 Gender, religiosity, university and having a person with a psychiatric condition in the student's surroundings: association with ATP-30 score. *Non-religious responses included students that are not religious or might be religious (those who answered "maybe")

\begin{tabular}{|c|c|c|c|c|}
\hline & \multicolumn{2}{|l|}{ ATP scores } & \multirow[b]{2}{*}{$\chi^{2}$} & \multirow[b]{2}{*}{$p$ value } \\
\hline & $\leq 90$ & $>90$ & & \\
\hline \multicolumn{5}{|l|}{ Gender } \\
\hline Male & $16(6.2 \%)$ & $241(93.8 \%)$ & \multirow[t]{2}{*}{1.56} & \multirow[t]{2}{*}{0.21} \\
\hline Female & $14(4.0 \%)$ & $336(96.0 \%)$ & & \\
\hline \multicolumn{5}{|l|}{ Universities } \\
\hline Public & $15(4.5 \%)$ & $297(95.2 \%)$ & \multirow[t]{2}{*}{0.22} & \multirow[t]{2}{*}{0.65} \\
\hline Private & $15(5.1 \%)$ & $280(94.9 \%)$ & & \\
\hline \multicolumn{5}{|l|}{ Religiosity } \\
\hline Religious & $21(5.4 \%)$ & $370(94.6 \%)$ & \multirow[t]{2}{*}{0.43} & \multirow[t]{2}{*}{0.51} \\
\hline Non-religious* & $9(4.2 \%)$ & $9(4.2 \%)$ & & \\
\hline \multicolumn{5}{|c|}{$\begin{array}{l}\text { Has any member of your surrounding been diagnosed with a psychiatric } \\
\text { conditions? }\end{array}$} \\
\hline Yes & $6(2.4 \%)$ & $249(97.6 \%)$ & \multirow[t]{2}{*}{6.3} & \multirow[t]{2}{*}{0.013} \\
\hline No & $24(6.8 \%)$ & $328(93.2 \%)$ & & \\
\hline
\end{tabular}

disease in the surroundings were significantly associated with ATP-30 scores ( $p$ value $=0.027$ and 0.018 , respectively) . Students having higher WHO-5 scores were more likely to have non-favorable attitudes towards psychiatry $(\mathrm{OR}=$ $0.978<1,95 \% \mathrm{CI}=0.958-0.997)$. In contrast, students in contact with psychiatric patients in their surroundings were approximately three times more likely to have a favorable attitude towards psychiatry $(\mathrm{OR}=3.012,95 \% \mathrm{CI}=1.209$ $7.5)$.

\section{Discussion}

Among all participants, $95.1 \%$ had a positive attitude towards psychiatry, while only $4.8 \%$ had a negative attitude with an average ATP-30 score in our sample of 111.95 over 150 (SD $=12.55$ ). In addition, $26.5 \%$ of participants reported that they consider psychiatry as a potential career choice. None of the demographic factors influenced the ATP-30 scores. Exposure to a patient with a diagnosed psychiatric illness in the student's surroundings and a lower WHO-5 well-being index were the only two significant factors that resulted in favorable attitudes towards psychiatry in the multivariate analysis.

\section{Favorable ATP-30 Score in Lebanese Medical Students}

When handing out such types of questionnaires in a developing Arab country, one would expect to have rather unfavorable attitudes towards psychiatry [3-5]. Surprisingly, and according to this study, medical students in Lebanon do not fall into the traditional "developed vs developing countries" paradigm. The ATP-30 average score of Lebanese medical students, which is 111.95 , did indeed surpass that of medical students in India (93.31), Egypt (99.31), Nigeria (103.6), 
Table 2 Answers from selected questions in the ATP-30 scale

\begin{tabular}{|c|c|c|c|c|c|c|c|}
\hline Questions from ATP-30 & Disagree strongly & Disagree & Neutral & Agree & Agree strongly & $\chi^{2}$ & $p$ value \\
\hline I would like to be a psychiatrist. & $65(10.7 \%)$ & $152(25 \%)$ & $216(35.6 \%)$ & $121(19.9 \%)$ & $53(8.7 \%)$ & 146.171 & 0.001 \\
\hline $\begin{array}{l}\text { Psychiatry has very little scientific information } \\
\text { to go on. }\end{array}$ & $100(16.5 \%)$ & $296(48.8 \%)$ & $123(20.3 \%)$ & $77(12.7 \%)$ & $11(1.8 \%)$ & 371.542 & 0.001 \\
\hline $\begin{array}{l}\text { These days psychiatry is the most important part } \\
\text { of the curriculum in medical schools. }\end{array}$ & $42(6.9 \%)$ & $159(26.2 \%)$ & $194(32 \%)$ & $167(27.5 \%)$ & $45(7.4 \%)$ & 172.201 & 0.001 \\
\hline $\begin{array}{l}\text { Psychiatric patients are often more interesting } \\
\text { to work with than other patients. }\end{array}$ & $13(2.1 \%)$ & $68(11.2 \%)$ & $198(32.6 \%)$ & $225(37.1 \%)$ & $103(17 \%)$ & 259.812 & 0.001 \\
\hline
\end{tabular}

Bahrain (105.79), and Hungary (106.4) [5, 10-13]. It is in the range of that of Germany (111.6), Austria (112.2), and Switzerland (111.9) [13].

\section{Factors Related to a Favorable ATP-30 Score}

\section{Demographics}

Demographic variables in this sample did not significantly impact the ATP-30 score, as shown in similar studies in other countries such as Serbia [14]. In contrast, another study found that more students from private universities report psychiatry as a potential career choice than students from public universities, which was not found in our Lebanese sample [15].

Also, it is noteworthy that, in the general Lebanese population, higher knowledge of mental illness was reported in the North of Lebanon, which was not the case in our medical students' sample [3].

\section{Religiosity}

The question of religiosity was raised in this study, especially since historical tension between religion and psychiatry did not subside yet, with US psychiatrists being overall less religious than other physicians [16]. Many Arab citizens stigmatize mental health conditions and consider that patients who struggle with psychiatric illnesses can be cured if brought closer to God, explaining the role attributed to religious healers in these countries [17]. Nonetheless, evidence has found that religiosity is not a protective factor against depression in a sample of Lebanese breast cancer patients [18]. As expected, after examining the data presented above, nonreligious medical students did not have significantly higher ATP-30 scores than religious students (Table 1).

\section{Being Acquainted with a Psychiatric Patient}

Being acquainted with a psychiatric patient is one of the two significant factors to more favorable ATP-30 scores identified in this study. This sensitization role was identified in other publications through attending a psychiatry/mental health club during medical school years, for instance [19-21]. This finding emphasizes the importance of continuous close contact with patients struggling with mental disorders, which gives medical students an insight into these patients' daily lives, possibly portraying the importance of good patient management and highlighting the role of the psychiatrist in society.

\section{ATP-30 and WHO-5}

Two scales were used in this questionnaire: the ATP-30 and the WHO-5. Interestingly, medical students who scored less on the WHO-5 scale, meaning that they had poorer psychological well-being at the time of the questionnaire, scored higher on the ATP-30 reflecting a more favorable opinion about psychiatry, psychiatrists, psychiatric hospitals, and psychiatric treatments at hand. In reality, physicians are not immune to stress, depression, anxiety, substance misuse, and other psychiatric conditions, but many studies suggest that psychiatrists are particularly more prone to depression and burnout [22, 23].

\section{Psychiatry as a Career Choice}

In this study, $26.5 \%$ of participants reported that they consider psychiatry as a potential career choice. A 2013 systemic review included 12,144 students from 74 medical schools in 22 different countries; psychiatry as a career choice was not very popular or appealing among these students overall [24]. This point is of particular interest, knowing that the shortage of psychiatrists has been an emerging concern in many countries such as the USA, where quantitative data estimated that the deficit in psychiatrists might hit alarming numbers of 14,280 to 31,091 psychiatrists in the USA in 2024 [25]. Third-world countries such as Lebanon are particularly more at risk, given that in many developing countries there is a continuing "braindrain," defined as the emigration of psychiatrists from developing to developed countries such as Canada, Australia, and the USA [26]. Numbers show that $40 \%$ of physiciansincluding psychiatrists - graduated from Lebanese medical schools from 1978 to 2004 are currently active physicians in the USA [27]. Thus, even though in our sample $8.7 \%$ strongly agreed to the statement "I would like to be a psychiatrist" and another $19.9 \%$ also agreed to this statement (Table 2), there is 
no guarantee that these individuals will be supplying the Lebanese psychiatrists' workforce.

\section{Individual Questions from the ATP-30}

This Lebanese sample's positive attitudes towards psychiatry are also manifested in the answers to several questions in the ATP-30 scale. For instance, only $1.8 \%$ strongly agreed that psychiatry has very little scientific information to go on, pointing out a possible non-scientific, philosophical basis for psychiatry. This particular issue has been addressed multiple times in similar studies and was found to be a negative factor discouraging students from pursuing psychiatry $[28,29]$. In another study, it even resulted along with other factors to psychiatry being ranked as the least attractive specialty [30]. One might be doubtful about psychiatric diagnoses because these are usually not based on physical findings, laboratory results, and imaging. Currently, the DSM-5 (The Diagnostic and Statistical Manual of Mental Disorders, Fifth Edition) manual is used in Lebanon to diagnose mental disorders. Even this categorical system was criticized several times, as in the paper by Allsopp et al. published in 2019, reporting heterogeneity in diagnosis classification [31]. Some of the points discussed in this paper were the overlap between criteria of diagnoses, as several symptoms were found in many diagnoses, and the absent role of trauma in the diagnosis of most psychiatric conditions, while trauma seems to have a leading role in their pathogenesis [32].

When asked if psychiatric patients are more interesting to work with than other patients, $17 \%$ strongly agreed and $2.1 \%$ strongly disagreed. Accordingly, other studies have also found that working with psychiatric patients is often considered by medical students as an intellectual challenge [29, 33], especially in multicultural contexts, where treatment guidelines may not be optimally applicable or evidence-based [34] and where proactive, creative thinking is required. Lebanon is a fundamental model of ethnic and religious diversity with the coexistence of 18 religious sects within its $10,452 \mathrm{~km}^{2}$.

The most controversial statement in this questionnaire was probably the one that tackled whether the psychiatry course would be the most important part of medical schools' curriculum. To this statement, $6.9 \%$ strongly disagreed, $26.2 \%$ disagreed, $32 \%$ were neutral, $27.5 \%$ agreed, and $7.4 \%$ strongly agreed. To illustrate the cardinal role of psychiatry in medicine, Kallivayalil cited Socrates: "It is impossible for the part to be well, if the whole is not well" [35]. Practically, there is an incontestable reform in medicine from paternalism to a patient-centered practice. Psychiatrists have the leading role in this reform given that they have both a general medicine background and training in behavioral healthcare; they have been described as "catalysts" of this reform by Raney [36]. In Lebanon, the psychiatry curriculum might be limited due to time constraints. Therefore, increasing mental health education in medical schools' curricula has been recommended to improve mental health services in Lebanon [6]. The gaps in a psychiatry curriculum would appear later on when primary care physicians would be unable to identify a psychiatric problem in patients with psychosomatic complaints, which is also a problem reported in Lebanon [6]. In an effort to evaluate the psychiatry curriculum at the Lebanese University, which is the only public sector university in Lebanon, we compared the ATP-30 scores of third-year students to that of fifth-year students, knowing that the psychiatry course is a four credits course $(40 \mathrm{~h})$ given in the fourth year of medical school. No significant difference was noted but both years had favorable attitudes (Fig. 1).

This study has several limitations; it could have been affected by a selection bias leading to a non-representative sample since the questionnaire has been sent electronically to medical students. Interns (sixth- and seventh-year medical students) were more likely to be busy during clinical rotations than other medical students, especially since data collection was conducted during the COVID-19 pandemic, leading to a lower response rate in these medical years. The response rate from certain universities (e.g., AUB) was also low, which renders a generalization about these universities difficult. In addition, information bias could have taken place if students answered in a way that does not truly reflect their opinions, to convey an improved picture of reality. Finally, there could have been a recall bias when the participants were asked about any acquaintance with a psychiatric patient.

In summary, Lebanese medical students have a favorable attitude towards psychiatry, which can be exploited to produce a larger psychiatric workforce in Lebanon, despite the ongoing brain-drain from Lebanon to the USA and European countries. This study showed that exposure to a patient with psychiatric illness yielded a more favorable outlook. Thus, early exposure could be a strategy used by Lebanese medical schools to ensure more awareness and positive perspectives and perhaps more medical students selecting psychiatry as a career choice. The strategy should also include appropriate implementations of policies regarding residency programs and updating psychiatry curricula in Lebanese medical schools.

\section{Declarations}

Disclosures On behalf of all authors, the corresponding author states that there is no conflict of interest.

\section{References}

1. Farhood L, Dimassi H, Lehtinen T. Exposure to war-related traumatic events, prevalence of PTSD, and general psychiatric morbidity in a civilian population from Southern Lebanon. J Transcult Nurs. 2006;17(4):333-40. 
2. World Health Organization. WHO-AIMS report on mental health system in Lebanon. World Health Organization, Beirut, Lebanon (2010)

3. Abi Doumit C, Haddad C, Sacre H, Salameh P, Akel M, Obeid S, et al. Knowledge, attitude and behaviors towards patients with mental illness: results from a national Lebanese study. PLoS One. 2019;16:14(9).

4. Demyttenaere K, Bruffaerts R, Posada-Villa J, Gasquet I, Kovess $\mathrm{V}$, Lepine J, et al. Prevalence, severity, and unmet need for treatment of mental disorders in the World Health Organization World Mental Health Surveys. Jama. 2004;291(21):2581-90.

5. Al-Krenawi A. Mental health practice in Arab countries. Curr Opin Psychiatry. 2005;18(5):560-4.

6. Burra P, Kalin R, Leichner PW, Waldron JJ, Handforth JR, Jarrett FJ, et al. The ATP 30 - a scale for measuring medical students' attitudes to psychiatry. Med Educ. 1982;16(1):31-8.

7. Shalaby AS. Attitude of an Egyptian sample of medical students toward psychiatry in comparison to previous studies using the Attitudes Towards Psychiatry (ATP-30) questionnaire. Acad Psychiatry. 2016;40(2):213-7.

8. Research Assignments - Slovin's Formula [Internet]. [cited 2020 May 18]. Available from: https://prudencexd.weebly.com/

9. WHO (Five) Well-Being Index (WHO-5) | Psychiatry \& Behavioral Health Learning Network [Internet]. [cited 2020 May 18]. Available from: https://www.psychcongress.com/ saundras-corner/scales-screeners/well-being-index/who-five-wellbeing-index-who-5

10. Parikh NC, Sharma PS, Chaudhary PJ, Gandhi HA, Banwari GH. Study of attitude of interns toward psychiatry: a survey of a tertiary level hospital in Ahmedabad. Ind Psychiatry J. 2014;23(2):143-8.

11. Wakil MA, Abdul IW, Abdulmalik JO, Salawu FK, Ahidjo A. The attitude and future career interest in psychiatry of medical students from the University of Maiduguri, North-eastern Nigeria. BOMJ. 2010;7 Available at http://bornomedicaljournal.com/current/.

12. Al-Ansari A. Attitude of Arabian Gulf University medical students towards psychiatry. Educ Health. 2002;15(2):180-8.

13. Warnke I, Gamma A, Buadze M, Schleifer R, Canela C, Strebel B, et al. Predicting medical students' current attitudes toward psychiatry, interest in psychiatry, and estimated likelihood of working in psychiatry: a cross-sectional study in four European countries. Front Psychiatry. 2018;9:49.

14. Maric NP, Stojiljkovic D, Milekic B, Milanov M, Bijelic J, JasovicGasic M. Change of students' interest in psychiatry over the years at school of medicine, University of Belgrade, Serbia. Isr J Psychiatry Relat Sci. 2011;48(1):42-8.

15. Aslam M, Taj T, Ali A, Badar N, Saeed F, Abbas M, et al. Psychiatry as a career: a survey of factors affecting students' interest in psychiatry as a career. McGill Journal of Medicine: MJM. 2009;12(1):7 12

16. Curlin FA, Odell SV, Lawrence RE, Chin MH, Lantos JD, Meador $\mathrm{KG}$, et al. The relationship between psychiatry and religion among US physicians. Psychiatr Serv. 2007;58(9):1193-8.

17. Peteet JR. Approaching religiously reinforced mental health stigma: a conceptual framework. Psychiatr Serv. 2019;70(9):846-8.

18. Abou Kassm S, Hlais S, Khater C, Chehade I, Haddad R, Chahine $\mathrm{J}$, et al. Depression and religiosity and their correlates in Lebanese breast cancer patients. Psycho-oncology. 2018;27(1):99-105.
19. Cutler JL, Alspector SL, Harding KJ, Wright LL, Graham MJ. Medical students' perceptions of psychiatry as a career choice. Acad Psychiatry. 2006;30(2):144-9.

20. Rajagopal S, Rehill KS, Godfrey E. Psychiatry as a career choice compared with other specialties: a survey of medical students. Psychiatr Bull. 2004;28(12):444-6.

21. Seow LS, Chua BY, Mahendran R, Verma S, Ong HL, Samari E, et al. Psychiatry as a career choice among medical students: a crosssectional study examining school-related and non-school factors. BMJ Open. 2018;8(8):e022201.

22. Summers RF, Gorrindo T, Hwang S, Aggarwal R, Guille C. Wellbeing, burnout, and depression among North American psychiatrists: the state of our profession. Am J Psychiatr. 2020;177(10): 955-64.

23. Kumar S, Hatcher S, Huggard P. Burnout in psychiatrists: an etiological model. Int J Psychiat Med. 2005;35(4):405-16.

24. Lyons Z. Attitudes of medical students toward psychiatry and psychiatry as a career: a systematic review. Acad Psychiatry. 2013;37(3):150-7.

25. Satiani A, Niedermier J, Satiani B, Svendsen DP. Projected workforce of psychiatrists in the United States: a population analysis. Psychiatr Serv. 2018;69(6):710-3.

26. Gureje O, Hollins S, Botbol M, Javed A, Jorge M, Okech V, et al. Report of the WPA task force on brain drain. World Psychiatry. 2009;8(2):115-8.

27. Akl EA, Maroun N, Major S, Chahoud B, Schünemann HJ Graduates of Lebanese medical schools in the United States: an observational study of international migration of physicians. BMC Health Serv Res. 2007;7(1):49.

28. Curtis-Barton MT, Eagles JM. Factors that discourage medical students from pursuing a career in psychiatry. Psychiatrist. 2011;35(11):425-9.

29. Abramowitz MZ, Bentov-Gofrit D. The attitudes of Israeli medical students toward residency in psychiatry. Acad Psychiatry. 2005;29(1):92-5.

30. Gat I, Abramowitz MZ, Bentov-Gofrit D, Cohen R. Changes in the attitudes of Israeli students at the Hebrew University Medical School toward residency in psychiatry: a cohort study. Isr J Psychiatry Relat Sci. 2007;44(3):194-203.

31. Allsopp K, Read J, Corcoran R, Kinderman P. Heterogeneity in psychiatric diagnostic classification. Psychiatry Res. 2019;279: $15-22$.

32. Floen SK, Elklit A. Psychiatric diagnoses, trauma, and suicidiality. Ann General Psychiatry. 2007;6(1):12.

33. Lee EK, Kaltreider N, Crouch J. Pilot study of current factors influencing the choice of psychiatry as a specialty. Am J Psychiatry. 1995;152:1066-9.

34. MCINTYRE JS. Usefulness and limitations of treatment guidelines in psychiatry. World Psychiatry. 2002;1(3):186-9.

35. Kallivayalil RA. The importance of psychiatry in undergraduate medical education in India. Indian J Psychiatry. 2012;54(3):20816.

36. Raney L. Integrated care: the evolving role of psychiatry in the era of health care reform. Psychiatr Serv. 2013;64(11):1076-8.

Publisher's Note Springer Nature remains neutral with regard to jurisdictional claims in published maps and institutional affiliations. 